exceed mere reduction in respiratory infections, such as reduction in diarrhoea burden and improvement in nutrition indices.

There has been considerable progress in vaccination strategies for the prevention of childhood infections and pneumonia. The importance of measles and pertussis vaccine in reducing child mortality is well established. Recent public health successes with large scale introduction of Haemophilus influenzae type b vaccine in developing countries ${ }^{19} 20$ also indicate that this vaccine must now become part of the universal expanded programme on immunisation vaccination package. Similar preliminary success with pneumococcal conjugate vaccine in Gambia ${ }^{21}$ and South Africa ${ }^{22}$ also raises the hope that we may soon have vaccines against the common bacterial pathogens which cause pneumonia.

Arch Dis Child 2007;92:286-288.

doi: 10.1136/adc.2006.111849

Correspondence to: $\operatorname{Dr} Z$ Z B Bhutta, Department of Paediatrics and Child Health, The Aga Khan University, Karachi, Pakistan; zulfiqar.bhutta@ aku.edu

Competing interests: None declared.

\section{REFERENCES}

1 Bryce J, Boschi-Pinto C, Shibuya K, WHO Child Health Epidemiology Reference Group, et al. WHO estimates of the causes of death in children. Lancet 2005;365: $1147-52$

2 Rudan I, Tomaskovic L, Boschi-Pinto C, WHO Child Health Epidemiology Reference Group, et al. Global estimate of the incidence of clinical pneumonia among children under five years of age. Bull World Health Organ 2004:82:895-903.

3 Wardlaw T, Salama P, Johansson EW, et al. Pneumonia: the leading killer of children. Lance 2006;368:1048-50.

4 WHO UNICEF. WHO UNICEF joint statement Management of pneumonia in community settings. 2004. WHO/FCH/CAH/04.06

5 Hazir H, Qazi SA, Nisar YB, et al. Comparison of standard versus double dose of amoxicillin in the treatment of non-severe pneumonia in children aged 2-5 months: a multi-centre, double blind, randomized controlled trial in Pakistan. Arch Dis Child 2007:92:291-7.

6 Hazir T, Nisar YB, Qazi SA, et al. Chest radiography in children aged 2-59 months diagnosed with non-severe pneumonia as defined by World Health Organization: descriptive multicentre study in Pakistan. BMJ 2006:333:629.

7 Jain A, Kumar P, Awasthi S. High ampicillin resistance in different biotypes and serotypes of Haemophilus influenzae colonizing the nasopharynx of healthy school-going Indian children. J Med Microbiol, 2006;55, (Pt 2):133-7

8 Echave P, Bille J, Audet C, et al. Percentage, bacterial etiology and antibiotic susceptibility of acute respiratory infection and pneumonia among children in rural Senegal. J Trop Pediatr 2003;49:28-32

9 Keeley DJ, Nkrumah FK, Kapuyanyika C. Randomized trial of sulfamethoxazole + trimethoprim versus procaine penicillin for the outpatient treatment of childhood pneumonia in Zimbabwe. Bull World Health Organ 1990:68:185-92.

10 Straus WL, Qazi SA, Kundi Z, et al. Antimicrobial resistance and clinical effectiveness of $\mathrm{CO}^{-}$ trimoxazole versus amoxycillin for pneumonia among children in Pakistan: randomised controlled trial. Pakistan Co-trimoxazole Study Group. Lancet 1998;352:270-4.

11 Rasmussen ZA, Bari A, Qazi S, et al. COMET (Cotrimoxazole Multicentre Efficacy) Study Group. Randomized controlled trial of standard versus double dose cotrimoxazole for childhood pneumonia in Pakistan. Bull World Health Organ 2005;83:10-19.

12 Catchup Study Group. Clinical efficacy of cotrimoxazole versus amoxicillin twice daily for treatment of pneumonia: a randomised controlled clinical trial in Pakistan. Arch Dis Child 2002;86:113-18.

13 Pakistan Multicentre Amoxycillin Short Course Therapy (MASCOT) pneumonia study group. Clinical efficacy of 3 days versus 5 days of oral amoxicillin for treatment of childhood pneumonia: a multicentre double-blind trial. Lancet 2002;360:835-41.

14 Agarwal G, Awasthi S, Kabra SK, ISCAP Study Group, et al. Three day versus five day treatment with amoxicillin for non-severe pneumonia in young children: a multicentre randomised controlled trial. BMJ 2004:328:791.

15 Bruce N, McCracken J, Albalak R, et al. Impact of improved stoves, house construction and child location on levels of indoor air pollution exposure in young Guatemalan children. J Expo Anal Environ Epidemiol 2004;14(Suppl 1):S26-33.

16 Kirkwood BR, Gove S, Rogers S, et al. Potential interventions for the prevention of childhood pneumonia in developing countries: a systematic review. Bull World Health Organ 1995:73:793-8.

17 Victora CG, Kirkwood BR, Ashworth A, et al. Potential interventions for the prevention of childhood pneumonia in developing countries: improving nutrition. Am J Clin Nutr 1999:70:309-20.

18 Luby SP, Agboatwalla M, Feikin DR, et al. Effect of hand washing on child health: a randomised controlled trial. Lancet 2005;366:225-33.

19 Cowgill KD, Ndiritu M, Nyiro J, et al. Effectiveness of Haemophilus influenzae type $b$ conjugate vaccine introduction into routine childhood immunization in Kenya. JAMA 2006;296:671-8.

20 Adegbola RA, Secka O, Lahai G, et al. Elimination of Haemophilus influenzae type $b$ (Hib) disease from The Gambia after the introduction of routine immunisation with a Hib conjugate vaccine: a prospective study. Lancet 2005;366:144-50.

21 Cutts FT, Zaman SM, Enwere G, Gambian Pneumococcal Vaccine Trial Group, et al. Efficacy of nine-valent pneumococcal conjugate vaccine against pneumonia and invasive pneumococcal disease in The Gambia: randomised, double-blind, placebo-controlled trial. Lancet 2005; 365: 1139-46.

22 Klugman KP, Madhi SA, Huebner RE, Vaccine Trialists Group, et al. A trial of a 9-valent pneumococcal conjugate vaccine in children with and those without HIV infection. N Engl J Med 2003;349:1341-8.

\title{
Children under pressure: an underestimated burden?
}

\section{Saverio Stranges, Francesco P Cappuccio}

\section{Perspective on the paper by Jackson et al (see page 298)}

$\mathrm{T}$ he study by Jackson et al ${ }^{1}$ represents a significant contribution to our knowledge in the area of hypertension research and related clinical practice. The definition of national blood pressure references for children and young adults, aged 4-23 years, living in Great Britain provides important, complementary information to the updated US guidelines on the management of high blood pressure in children and adolescents aged 117 years, $^{2}$ as well as to earlier attempts to define normative blood pressure values from other countries. ${ }^{3-7}$ In addition, these centiles will integrate existing charts in the UK regarding other important parameters (eg, body mass index), thereby allowing a more comprehensive characterisation of the health of children. Some distinctive aspects of the study by Jackson et al ${ }^{1}$ should be highlighted: the representative and large sample size of the seven surveys from which blood pressure data were drawn; the consistent method applied for blood pressure measurements; the use of a statistical technique such as the LMS method to construct blood pressure centiles, which accounts for the skewness (L), median (M), and coefficient of variation (S) of the blood pressure distribution. ${ }^{8}$ Indeed, this statistical tool had been previously used in a German study to derive normalised reference values for the 24-h ambulatory blood pressure in children and adolescents aged 5-20 years.?

In addition to the statistical value of their contribution, the study by Jackson $e t$ al is particularly relevant because it gives emphasis to a significant problem in the medical field: hypertension in childhood. In the past few decades, the definition of normative values for blood pressure in the paediatric age range has been increasingly recognised as an important issue in clinical practice and public health because of the changing patterns in the epidemiology and associated determinants of hypertension among children and young adults. Several reasons justify the increasing attention to 
this issue. Firstly, essential hypertension, especially in school-age children and adolescents, has become a condition of clinical and epidemiological relevance at least comparable to that associated with secondary forms of childhood hypertension. ${ }^{9}$ Secondly, as indicated by Jackson et al, there is substantial evidence showing the tracking of blood pressure from childhood to adulthood at a population level. ${ }^{10}$ Thirdly, hypertension in childhood may cause end-organ damage (eg, left ventricular hypertrophy) and predispose children to the early development of atherosclerosis and the occurrence of cardiovascular sequelae in adulthood. ${ }^{11}$ Therefore, greater attention to blood pressure early in life has the potential to generate long-term benefits on cardiovascular health. ${ }^{12}$ Finally, common determinants of hypertension in adulthood have increasingly become important medical issues in children and adolescents. The most important example is obesity-related hypertension, which is a condition that is acquiring epidemic dimensions in the UK as well as worldwide. ${ }^{13}$ The finding of Jackson et al of a strong association between body weight/ obesity and high blood pressure further corroborates this notion.

A further interesting result observed in this study is the high percentage $(23 \%)$ of young males with systolic blood pressure levels above the British Hypertension Society cut-off for hypertension (ie, $>140 \mathrm{~mm} \mathrm{Hg}){ }^{14}$ This finding needs to be cautiously interpreted, however, as it is based on blood pressure measurements obtained on a single occasion, which may lead to some degrees of misclassification (overdiagnosis) because of the potential for a "white coat" effect $^{15}$ and regression to the mean on subsequent measurements. ${ }^{16}$ Further considerations refer to the age range of the study participants with a large proportion consisting of older teenagers and young adults (up to 24 years), and the use of an oscillometric device that may overestimate systolic blood pressures compared with values obtained by auscultation. ${ }^{17}$ However despite these methodological issues, it should be noted that the apparently high prevalence of hypertension among young males found by Jackson et al is comparable to figures reported in recent studies across different populations of children and adolescents. ${ }^{18-21}$ For example, using a similar approach to measure resting blood pressure (ie, three consecutive measurements with an oscillometric device), a school-based survey of 3589 children and adolescents conducted in Quebec, Canada, showed prevalence percentages of high-normal or increased systolic blood pressure to be $12 \%, 22 \%$, and $30 \%$ among 9, 13 and 16-year-old males, respectively, with lower figures among females, based on the US cut-off values. ${ }^{18}$ This is consistent with the British data. Similar figures were observed in a sample of minority schools from three US locations; however, only eight-grade adolescents were included. ${ }^{21}$ Together, these data support the existence of an evolving epidemic of hypertension in youth, which is closely associated with a parallel epidemic of obesity. ${ }^{13}$ In addition, these data indicate the potential for future increases in adult blood pressure levels and in the prevalence of hypertension in the next generations, which could determine a rise in cardiovascular morbidity and mortality. Open questions in this area pertain to: the observed sex differences among children in hypertension prevalence, which tend to be magnified with increasing age; the predominance of systolic hypertension, which could be partially related to excess body weight and fat distribution; the role of other determinants in the development of high blood pressure in youth (eg, diet, decreased physical activity, social factors, ethnicity, heritability, sleep disorders $)^{22}{ }^{23}$ beyond body weight, which does not explain the overall variability in blood pressure levels and accounts only in part for the observed increase in the mean levels of blood pressure. ${ }^{24}$ For example, findings on the role of ethnicity in childhood hypertension have been inconsistent, with the observed ethnic differences often explained by differences in body size and fat distribution. ${ }^{19-21}{ }^{25}$ However, more data are needed to understand the interaction between ethnicity and environmental stimuli over the life course, which may result in ethnic differences in blood pressure levels in adulthood.

The information provided by Jackson $e t$ al highlights the importance of performing routine blood pressure screenings in childhood for the early detection of high blood pressure levels, thus allowing the implementation of timely preventive and therapeutic measures. Nevertheless, some unresolved issues deserve further consideration. Firstly, there is still concern about the accuracy of blood pressure measurements in large epidemiological studies because of the aforementioned misclassification issues, which are particularly critical in the paediatric age range. ${ }^{26}$ In addition, the comparability across studies is often hampered by the use of different measurement methods. Moreover, the use of oscillometric devices is still a controversial issue despite the efforts made to validate this tool Therefore, as recommended by Jackson et al, the proposed centiles need to be applied with caution when blood pressures are measured by auscultation.
Secondly, the difficulty in defining normative blood pressure levels in children has been due to the paucity of data associating childhood hypertension with cardiovascular risk in adulthood. However, ongoing longitudinal investigations should provide new insights into the long-term significance of high blood pressure in childhood, and of its interaction with other cardiovascular risk factors. ${ }^{27-29}$ Finally, although welldocumented in adults, there is still uncertainty about the role of environmental determinants of hypertension in children. Indeed, while the evidence on the importance of excess body weight in the development of high blood pressure in children is substantial, findings on the effects of other determinants such as dietary factors are less persuasive. ${ }^{30}$ In particular, there is a paucity of data regarding the efficacy of dietary and other lifestyle modifications in the prevention and management of high blood pressure among children. Recent findings from small-scale studies suggest that shortterm lifestyle interventions including dietary changes may produce beneficial effects on blood pressure and other components of the metabolic syndrome in overweight children. ${ }^{31}{ }^{32}$ For instance, compelling evidence has become available for a reduction in salt intake in infants and children to reduce the rise in blood pressure with age and the ensuing risk of hypertension. $^{33}$ Long-term and larger intervention trials are needed to evaluate whether the observed benefits are sustainable and clinically relevant within the paediatric age range.

Arch Dis Child 2007;92:288-290.

doi: 10.1136/adc.2006.110643

\section{Authors' affiliations}

Saverio Stranges, Francesco P Cappuccio, Clinical Sciences Research Institute, Warwick Medical School, Coventry, UK

Correspondence to: Professor F P Cappuccio, Cardiovascular Medicine \& Epidemiology, Clinical Sciences Research Institute, Warwick Medical School, CSB at UHCW Campus, Clifford Bridge Road, Coventry CV2 4DX, UK; cvme@warwick.ac.uk

Competing interests: FPC is a member of the Executive Committee and Treasurer of the British Hypertension Society.

\section{REFERENCES}

1 Jackson LV, Thalange NK, Cole TJ. Blood pressure centiles for Great Britain. Arch Dis Child 2007;92:298-303.

2 National High Blood Pressure Education Program Working Group on High Blood Pressure in Children and Adolescents. The fourth report on the diagnosis, evaluation, and treatment of high blood pressure in children and adolescents. Pediatrics 2004; 1 14:555-76. 
3 De Man SA, André JL, Bachmann H, et al. Blood pressure in childhood: pooled findings of six European studies. J Hypertens 1991;9:109-14.

4 Sharma BK, Sagar S, Wahi PL, Talwar KK, Singh S, Kumar L. Blood pressure in schoolchildren in Northwest India. Am J Epidemiol 1991;134:1417-26.

5 Menghetti $E$, Virdis R, Strambi $M$, et al. Blood pressure in childhood and adolescence: the Italian normal standards. J Hypertens 1999; 17:1363-72.

6 Blake KV, Gurrin LC, Evans SF, et al. Reference ranges for blood pressure in preschool Australians, obtained by oscillometry. J Paediatr Child Health 2000;36:41-6

7 Wühl E, Witte K, Soergel M, et al. Distribution of 24-h ambulatory blood pressure in children: normalized reference values and role of body dimensions. J Hypertens 2002;20:1995-2007.

8 Cole TJ, Green PJ. Smoothing reference centile curves: the LMS method and penalized likelihood. Stat Med 1992;11:1305-19.

9 Sinaiko AR. Hypertension in children. N Engl J Med 1996;335:1968-73

10 Whincup PH, Cook DG, Geleijnse JM. A life course approach to blood pressure. In: Kuh D, BenShlomo Y, eds. A Life Course Approach to Chronic Disease Epidemiology. Oxford: Oxford University Press, 2004:218-39.

11 Celermajer DS, Ayer JGJ. Childhood risk factors for adult cardiovascular disease and primary prevention in childhood. Heart 2006;92:1701-6.

12 McGill HC Jr, McMahan CA. Starting earlier to prevent heart disease. JAMA 2003;290:2320-2.

13 Sorof J. Daniels S. Obesity hypertension in children a problem of epidemic proportions. Hypertension 2002;40:441-7.

14 Williams B, Poulter NR, Brown MJ, et al. British Hypertension Society guidelines for hypertension management 2004 (BHS-IV): summary. BMJ 2004:328:634-40.

15 Sorof JM, Poffenbarger T, Franco T, et al Evaluation of white coat hypertension in children: importance of the definitions of normal ambulatory blood pressure and the severity of casual hypertension. Am J Hypertens 2001;14:855-86.

16 Davis CE. The effect of regression to the mean in epidemiologic and clinical studies. Am J Epidemiol 1976;104:493-8.

17 Park MK, Menard SW, Yuan C. Comparison of auscultatory and oscillometric blood pressures. Arch Pediatr Adolesc Med 2001;155:50-3.

18 Paradis G, Lambert M, O'Loughlin J, et al. Blood pressure and adiposity in children and adolescents. Circulation 2004; 110:1832-8.

19 Sorof JM, Lai D, Turner J, et al. Overweight, ethnicity, and the prevalence of hypertension in school-aged children. Pediatrics 2004; 113:475-82.

20 Jafar $\mathrm{TH}$, Islam $\mathrm{M}$, Poulter $\mathrm{N}$, et al. Children in South Asia have higher body mass-adjusted blood pressure levels than white children in the United States: a comparative study. Circulation 2005;111:1291-7.

21 Jago R, Harrell JS, McMurray RG, et al. Prevalence of abnormal lipid and blood pressure values among an ethnically diverse population of eighth-grade adolescents and screening implications. Pediatrics 2006;117:2065-73.

22 Reilly JJ, Armstrong J, Dorosty AR, et al. Early life risk factors for obesity in childhood: cohort study. BMJ 2005;330:1357-63.

23 Currie A, Cappuccio FP. Sleep in children and adolescents: a worrying scenario. Nutr Metab Cardiovasc Dis. In press.
24 Muntner P, He J, Cutler JA, et al. Trends in blood pressure among children and adolescents. JAMA 2004;291:2107-13.

25 Rosner B, Prineas RJ, Daniels SR, et al. Blood pressure differences between blacks and whites in relation to body size among US children and adolescents. Am J Epidemiol 2000;151:1007-19.

26 Gillman MW, Cook NR. Blood pressure measurement in childhood epidemiological studies. Circulation 1995;92:1049-57.

27 Davis PH, Dawson JD, Riley WA, et al. Carotid intimal-medial thickness is related to cardiovascular risk factors measured from childhood through middle age: the Muscatine Study. Circulation 2001;104:2815-19.

28 Li S, Chen W, Srinivasan SR, et al. Childhood cardiovascular risk factors and carotid vascular changes in adulthood: the Bogalusa Heart Study JAMA 2003;290:2271-6.

29 Raitakari OT, Juonala $M$, Kähönen $M$, et al. Cardiovascular risk factors in childhood and carotid artery intima-media thickness in adulthood: the Cardiovascular Risk in Young Finns Study. JAMA 2003;290:2277-83.

30 Simons-Morton DG, Obarzanek E. Diet and blood pressure in children and adolescents. Pediatr Nephrol 1997; 11:244-9.

31 Monzavi R, DreimaneD, GeffnerM, etal. Improvemen in risk factors for metabolic syndrome and insulin resistance in overweight children who are treated with lifestyle intervention. Pediatrics 2006;117:e1111-18.

32 Chen AK, Roberts CK, Barnard RJ. Effect of a shortterm diet and exercise intervention on metabolic syndrome in overweight children. Metabolism 2006:55:871-8.

33 He FJ, MacGregor GA. Importance of salt in determining blood pressure in children. Meta-analysi of controlled trials. Hypertension 2006;48:861-9. 